\title{
Does video -based and live attribution training improve college freshman performance on academic -based tasks?
}

\author{
Tasneem Doctor \\ West Virginia University
}

Follow this and additional works at: https://researchrepository.wvu.edu/etd

\section{Recommended Citation}

Doctor, Tasneem, "Does video -based and live attribution training improve college freshman performance on academic -based tasks?" (2004). Graduate Theses, Dissertations, and Problem Reports. 2556.

https://researchrepository.wvu.edu/etd/2556

This Dissertation is protected by copyright and/or related rights. It has been brought to you by the The Research Repository @ WVU with permission from the rights-holder(s). You are free to use this Dissertation in any way that is permitted by the copyright and related rights legislation that applies to your use. For other uses you must obtain permission from the rights-holder(s) directly, unless additional rights are indicated by a Creative Commons license in the record and/ or on the work itself. This Dissertation has been accepted for inclusion in WVU Graduate Theses, Dissertations, and Problem Reports collection by an authorized administrator of The Research Repository @ WVU.

For more information, please contact researchrepository@mail.wvu.edu. 
Does Video-Based and Live Attribution Training Improve College Freshman

Performance on Academic-Based Tasks?

\title{
Tasneem Doctor
}

\author{
Dissertation submitted to the \\ College of Human Resources and Education \\ at West Virginia University \\ in partial fulfillment of the requirements \\ for the degree of
}

\author{
Doctor of Education \\ In \\ Educational Psychology \\ Richard T. Walls \\ Patricia A. Haught \\ Diane T. Woodrum \\ Ernest R. Goeres \\ Floyd L. Stead \\ Department of Advanced Educational Studies
}

Morgantown, West Virginia

2004

Keywords: Attribution Training, Attribution Theory, Locus of Control, Study Strategies, Video-Based Attribution Training

Copyright 2004 Tasneem Doctor 


\section{Abstract \\ Does Video-Based and Live Attribution Training Improve College Freshman Performance on Academic-Based Tasks? \\ Tasneem Doctor}

This study examined the effects of attribution training (an intervention designed to increase motivation and achievement) on undergraduate students' effort and performance. The sample consisted of 93 undergraduate, freshman students enrolled in a study strategies course during the fall semester. The attribution training was varied for each student by attribution training mode (live, video, or control), time of semester (beginning or end), and gender of script reader (male or female). Other independent variables examined included gender of the participant (male or female) and ACT and SAT scores (low versus high). Change Scores (post minus pre) served as dependent variables for both GRE practice score and homework completion rate. Results indicated that attribution training increased homework completion rate when training was carried out via the live video mode of attribution training. Students also increased homework completion rate at the beginning as opposed to the end of the semester. Students did better on GRE practice scores when attribution training was carried out by a male as compared to a female presenter. This research will help guide future researchers interested in examining the effectiveness of various modes of attribution training. 


\section{Acknowledgements}

I thank my family and friends who have encouraged and supported me throughout this process. Very special thanks go to Anagloria Rodriquez and Michael Corrigan whose help I could not have done without. I am also grateful to my committee, Dr. Richard Walls, Dr. Patricia Haught, Dr. Ernie Goeres, Dr. Diane Woodrum, and Dr. Floyd L. Stead for their help and encouragement. Finally, I am grateful to Ann Crabtree for encouraging me throughout the dissertations process. I could not have done this without all of you. Thank you. 
TABLE OF CONTENTS

CHAPTER 1

INTRODUCTION AND LITERATURE REVIEW................... 1

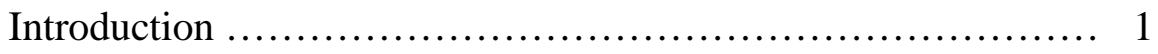

Statement of the Problem .................................. 2

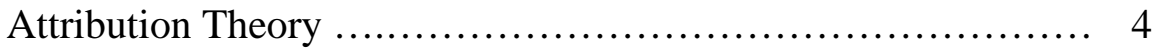

Locus of Control ......................................... 5

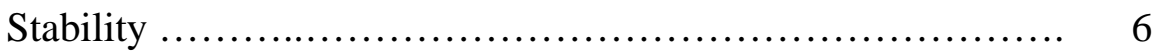

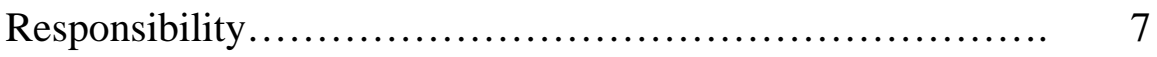

Attribution Theory and Achievement $\ldots \ldots \ldots \ldots \ldots \ldots \ldots \ldots \ldots . . . \ldots$

Attribution Styles and Academic Achievement .............. 11

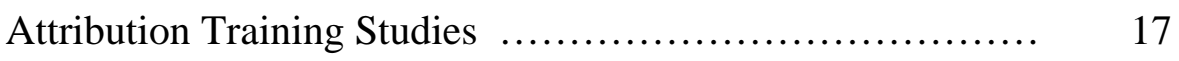

Video-Based Attribution Training Studies.................... 21

CHAPTER 2

METHOD ..................................................... 32

Participants........................................... 32

Study Strategies Course $. . . \ldots \ldots \ldots \ldots \ldots \ldots \ldots \ldots \ldots \ldots \ldots \ldots . . \ldots \ldots$

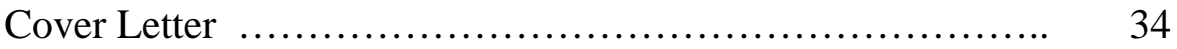

Procedure............................................... 34

Training Video-Based and Live Testimonial Script Readers ... 36

Research Questions ..................................... 38

Research Question $1 \ldots \ldots \ldots \ldots \ldots \ldots \ldots \ldots \ldots \ldots \ldots . . . \ldots$

Research Question 2 ........................... 39 
Research Question 3 .............................. $\quad 40$

Research Question 4 .............................. $\quad 40$

Research Question 5 ............................. 41

Research Design ...................................... 42

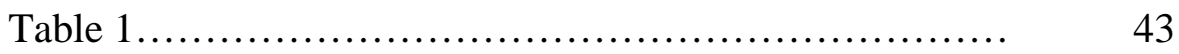

\section{CHAPTER 3}

RESULTS................................................ 44

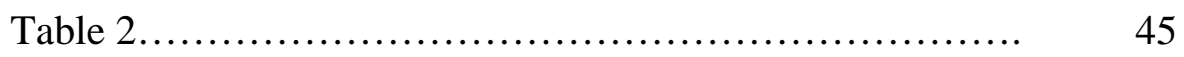

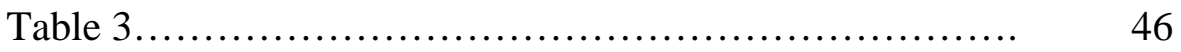

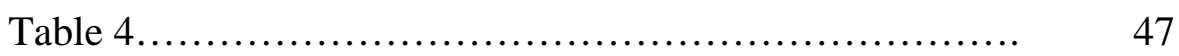

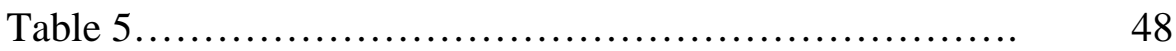

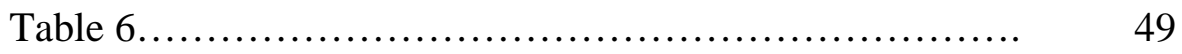

\section{CHAPTER 4}

DISCUSSION ................................................ 51

Limitations........................................... 54

Suggestions for Future Research......................... 58

REFERENCES..................................................... 63

APPENDIX A Cover Letter......................................... 68

APPENDIX B Script for Video and Live-Based Script Readers ............. 6 


\section{LIST OF FIGURES}

Figure 1 Weiner's (1994) Theory of Common Causal Attributions in Academic Settings............................................

Figure 2 Attribution Style and Academic Achievement: Summary

of Findings .............................................

Figure 3 Attribution Training Studies: Summary of Findings 


\section{CHAPTER 1}

Introduction and Literature Review

Today, we live in a world that places great importance on educational success. Due to the advances in technology and the greater reliance on machines rather than humans for simple and even advanced tasks, jobs that require little or no higher education are few in number. In many ways, personal success and economic security are dependent on the extent to which individuals are able to successfully complete higher education. In addition, as this trend continues, a greater number of individuals are completing graduate and professional degrees. Since more students are interested in advancing beyond a bachelor's degree, the competition for acceptance into these types of programs is becoming more stringent. As a result, it is of utmost importance to perform successfully in higher education. Struggling students, such as those on academic probation and/or third and fourth semester freshman, need support and possibly interventions in order to help them overcome their struggles so that they can succeed in the future. Most colleges have programs in place that target struggling students with the goal of improving academic performance. Many of these programs include a course that teaches study strategies and general tips for succeeding in college.

\section{Introduction}

One useful intervention that is often ignored is the use of attribution training to help students develop more positive attributions about their ability to succeed in college. Attribution theory attempts to identify how students explain the reasons for their success or failure in academic settings. Students tend to have four main reasons that explain their rationales for success or failure, which include ability, effort, luck, and task difficulty. 
Researchers have found that attribution training focusing on modifying effort and strategies, rather than ability, can motivate students to work harder and perform more successfully on academic tasks following the training (Wilson \& Linville, 1982; 1985).

\section{Statement of the Problem}

Attribution training, as it is typically conducted, requires a lot of time and effort. Teachers, graduate students, or paraprofessionals typically have to be trained in order to effectively carry out attribution training. Furthermore, attribution training is typically completed over the course of several weeks, which usually means that implementing attribution training requires multiple volunteers to carry out the study, and these volunteers must be available for an extended amount of time. Most of the research that has been conducted on attribution training has used research assistants and teachers to carry out the attribution training programs. Teachers and research assistants usually receive instruction on how to carry out the attribution training appropriately, usually over multiple training sessions. Pearl (1982) acknowledged that because attribution training is so time-consuming, it may not be an efficient approach in terms of motivating students. However, video-based attribution training requires less time and less training of participants, and may be a more time-efficient and effective way to carry out this type of training. Individuals conducting the training could memorize a script; and, therefore, extensive training would not be necessary. In addition, showing this short video during school hours would add only a minor disruption in classroom schedules as opposed to several days of attribution training.

Due to the benefits of video-based attribution training, as mentioned above, the current study will examine the effects of video-based attribution training on 
undergraduate students. Few studies have been conducted on this topic; therefore, the studies presented in this review of literature will provide further information regarding the effectiveness of video-based attribution training. These studies have found that attribution training that occurs in a single presentation can successfully improve student performance (Craske, 1985; Wilson \& Linville, 1982; 1985). In addition, one-shot attribution training via videotape obtained similar, positive outcomes when compared to attribution training over multiple sessions (Craske, 1985; Wilson \& Linville, 1982; 1985). When using videotapes to conduct attribution training, individuals who volunteer to carry out the training can be videotaped on their own time. This makes scheduling a lesser problem because there is a larger window of time for volunteers to carry out the attribution training.

Although both types of one-shot attribution training (video and live) have proven to be effective (Holschuch, Nist, \& Olejnik, 2001; Robertson, 2000; Wilson \& Linville, 1982), no known research has been conducted that involves carrying out both live and video-based attribution training for the purposes of comparing the effectiveness of each approach. This information would be beneficial because video-based attribution training is easier to carry out than live attribution training. In addition, one videotape can be used over and over again. Once a tape is made, it can be made available for viewing in several settings, such as freshman orientations, study skills classes, and classes designed for struggling students. As a result, one tape can get much more use than one live attribution training session. Therefore, it would be important for researchers to identify how live and video-based attribution training programs compare in terms of their effectiveness on student achievement. 
Since no known studies have identified differences in effectiveness between live and video-based attribution training, the main goal of the present study is to answer this particular research question. One male and one female, both senior-level pre-service teaching majors, volunteered to be script readers for the basis of this attribution training. Both script readers will memorize a prepared script (see Appendix B) that expresses his or her struggles in English 101. This script describes how he or she overcomes his or her struggles and succeeds in this class. Both script readers will memorize and present this script on video. Each video (male and female) will be shown to two different sections of a study strategies course. The male and female script readers also will present this same information in a live-testimonial format in front of one additional section of a study strategies class, during a regularly scheduled class meeting for the study strategies course. Effects of both attribution-training programs will be measured using two dependent variables. The dependent variables will be (a) sample practice questions from the Graduate Record Examination measured one week before and one week after attribution training, and (b) homework completion rate measured on the Friday before training and on the second Friday after training. Homework completion rate will be collected on the Friday prior to and the Friday following attribution training in order to get a full week's measure of homework completion rate.

\section{Attribution Theory}

Attribution training was developed based on the information derived from attribution theory. Attribution theory attempts to identify how students explain the reasons for their success or failure. People tend to ask themselves why certain things occur, and as a result, they search for the causes. Particularly, in an educational context, 
individuals may ask themselves: "Why did I do so poorly on the science test?" or "What caused me to make an A on my social studies test?” Weiner (1994a) contended that there are three main components related to attribution theory: locus of control, stability, and responsibility.

Locus of Control. The first component is locus of control. Locus means location and locus of control deals with whether persons believe that causality lies within themselves (I succeeded because I worked hard) or outside of themselves (I succeeded because I was lucky). Rotter (1990) defines this sense of control or locus of control as the extent to which an individual believes that he or she has control over an outcome. If an outcome is believed to be dependent on personal behavior or attributes such as effort or ability, it is considered to be internal. On the other hand, if an outcome is believed to be dependent on factors outside of the person such as luck, fate, or circumstance it is considered to be external.

Studies suggest that both internal and external loci of control are important predictors of academic achievement (Crandall, Katkovsky, \& Crandall, 1965; Hjelle, 1970; Messer, 1972). Kaiser (1975) found that individuals with an internal locus of control attributed their grades on a test to internal reasons (i.e., study habits, effort, knowledge of subject matter) while externals' attributions were related to external factors (i.e., difficulty of the test/subject matter, ability to guess, poor instructor). Most research focusing on locus of control has found that individuals who have an internal locus of control tend to have higher levels of academic achievement than those with an external locus of control (Findley \& Cooper, 1983). Hjelle (1970) found that undergraduate students with an internal locus of control have higher GPA's. Maqsud (1993) conducted 
a study, which concluded that individual variables, such as locus of control and intelligence, play important roles in meeting the goals of school. Maqsud (1993) concluded that students with an internal locus of control possibly do better academically because an internal locus of control is associated with greater use of academic-relevant information that would foster superior academic performance regardless of course content. Therefore, it may be that an internal locus of control is associated with the utilization of effective study habits.

Stability. Stability is the second component of attribution theory. Some aspects of causality can be changed or manipulated by a student while others cannot. For example, ability and task difficulty are stable because they cannot be easily changed or manipulated. On the other hand, effort and luck are unstable because students' amount of luck or effort is very likely to change from one situation to the next. This component is important to academic achievement because students’ perceptions regarding stability can help them to conceptualize how they think they will perform in the future. In general, if a student believes that previous successes or failures on tasks were a result of stable factors, they will be more certain about their expectations for future performance on similar tasks. However, if students believe unstable factors were responsible for their previous successes or failures, they will be less sure about future performance because they know that there could be shifts in performance due to changes that could occur with these unstable factors. Therefore, it is easier to predict future successes based on ability than on effort (Weiner, 1994b).

Although stable factors may sound more desirable because they help students feel more aware of future outcomes, this is not always the case. For example, Weiner, Cook, 
Heckhausen, and Meyer (1971) found that high attributes to a stable factor that caused failing decreased individuals’ beliefs that they will be able to succeed in the future. When students believe that failing is due to a stable factor, they are more likely to think that they will probably fail in the future, and therefore, they are less motivated to try. On the other hand, attributions of failure to unstable factors such as luck or effort facilitated continued performance because students do not necessarily believe that they are doomed to failure in the future. Their research also found that attributions of perceived outcome related to unstable factors tend to mediate persistence in the face of failure. However, stability can also be positive for a students’ perceptions of future performance, particularly if he or she has high ability. If students believe that they succeeded in a task due to high ability, then it is likely that they will expect to succeed in the future based on this perception of ability. In addition, Weiner (1994a) stated that students who believed that their success was due to ability, experienced feelings of competence and pride. Most research on stability has focused on students’ expectations regarding subsequent performance (Weiner \& Kukla, 1970; Weiner \& Peter, 1973).

Responsibility. Responsibility is the third component of attribution theory. Responsibility, in this context, refers to what is within or outside of students' control. For example, students are responsible for how much effort they put out, just as teachers are responsible for the difficulty of the task. However, students are not responsible for luck or ability because these aspects of causality are not subject to volitional control. Therefore, if a student believes that they failed at a task that was within their control, they often experience feelings of guilt. Likewise, if students believe that they succeeded at a task that was within their control, they often feel proud (Weiner, 1994a; b). When 
students fail at a task that they perceive as task as being outside of their control, they typically experience feelings of anger toward the institution or persons in control. Similarly, when students succeed at a task that they perceive as task as being outside of their control, they typically feel lucky or thankful.

Both the responsibility and locus of control dimensions of attribution theory contribute to what Seligman (1975) referred to as learned helplessness. Seligman (1975) pointed out that students who believe that the majority of the events in their lives are outside of their control, have developed learned helplessness. Learned helplessness is detrimental to intrinsic motivation because learned-helpless students believe that their efforts have no bearing on academic outcomes. As a result, these students frequently fail to turn in homework and other assignments, and therefore miss opportunities to practice and build academic skills. Learned helplessness, therefore, ends up causing cognitive deficits that occur from a lack of effort (controllable) as opposed to a lack of ability (uncontrollable).

Attribution Theory and Achievement. Weiner (1979) suggested that in achievement-related settings the most common attributes fall under four categories including ability, effort, task difficulty, and luck (refer to Figure 1). Ability and effort represent an internal locus of control while task difficulty and luck represent an external locus of control. In the same manner, ability and task difficulty are stable attributes while effort and luck are unstable attributes. Weiner (1972) provided descriptions of how individuals determine causal ascriptions for each of these four categories. First, Weiner states that "general ability is inferred from the number, percentage, and pattern of success experiences at prior achievement activities, considered in conjunction with the perceived 
Figure 1

Weiner's (1994a) Theory of Common Causal Attributions in Academic Settings

\begin{tabular}{|l|l|}
\hline Dimension Classification & Reason for Failure \\
\hline Internal-Stable-Uncontrollable & Ability \\
\hline Internal-Unstable-Controllable & Effort \\
\hline External-Unstable-Uncontrollable & Task Difficulty \\
\hline External-Unstable-Uncontrollable & Luck \\
\hline
\end{tabular}


difficulty of the attempted task.” In addition, specific task ability may be inferred by the amount of previous successes or failures on the specific task or tasks that are similar to a given task. For example, if students have had many successful experiences with algebra, it is likely that they may have a high perception of ability for geometry as well since it is a similar task. Second, effort refers to perceptions related to how hard individuals think that they have tried on any given task. Individuals often use performance outcome information to develop perceptions related to effort. In most cases, if students succeed on an outcome, it is likely that they believe that this outcome is a result of hard work. Third, task difficulty is usually determined by examining how others did on a task. For example, if more than half of the class failed a task, a student may perceive that task as being difficult. However, if almost all students succeed at a task, it will most likely be considered as easy. Finally, ascriptions of luck are generally developed by examining the basic structure of a task or by examining unique events. If a task is considered to be independent and random, individuals usually ascribe luck as the source of causation for an outcome. Such tasks include flipping a coin, playing the lottery, or guessing a number. Unique events, such as experiencing a success after many failures or hitting a homerun after striking out ten times, are usually thought to be determined by luck. Weiner (1972) contended that attribution errors commonly occur because individuals tend to overestimate randomness and the fluctuations of events.

Frieze (1976) completed a study that supported the notion that ability, effort, task difficulty, and luck are common descriptions of causality in academic settings. This study described a scenario in which an individual either succeeded or failed at a given task. Participants were given very limited information about the situation such as "You 
received a very high score on an exam” and then were asked what additional information should be provided before a decision regarding causality be made. For academic-related situations, the majority of the participants requested information related to ability, effort, task difficulty, and luck. Furthermore, Weiner (1979) found that of these four factors, effort and ability tend to have the most salient effect on performance. For example, when teachers and students are given real or imagined events and they are then asked to attribute what caused a success or failure related to these events, they are able to come up with many attributions. However, when reviewing the attributions that are given, the ones that come up frequently and also appear to be the most salient and general are effort and ability. The following section will examine how attribution theory can be applied via attribution training in order to produce positive academic outcomes.

Attribution Styles and Academic Achievement

Many studies have been conducted in order to identify the relationship attributional style has to academic achievement (Beyer, 1998; Brownlow \& Reasinger, 2001; Martinez \& Sewell, 2000; Peterson \& Barrett, 1987). Similar findings have been identified using different populations including college students, students in elementary and middle school, and students with disabilities. The findings suggest that particular attribution styles are related to higher academic achievement. Several studies have made this conclusion by conducting studies in which scenarios and open-ended questions are used to measure students' attribution style. For example, Peterson and Barrett (1987) studied the attribution styles of 87 freshman students (28 males and 59 females) attending Virginia Tech. These students were recruited from an introductory psychology course during the first two weeks of the academic school year. All students chosen for the study 
were undeclared, liberal arts majors. In order to examine attribution style, students were presented with 12 negative academic scenarios. For each hypothetical scenario, students were asked to think about the situation as if it were happening to them. The specific question was stated as follows: "If such a situation were to happen to you, what do you feel would have caused it? While events have many causes, we want you to pick only one--the major cause of this event if it happened to you. Please write this cause in the blank provided after each event” (Peterson \& Barrett, 1987, p. 604). After students responded to the scenario, they were asked to self-rate their response on a seven-point Likert scale. They rated each cause according to its internality, stability, and globality. An average score was obtained for each dimension across events and then across dimensions. Composite scores for each attribution style ranged from one to seven. In order to examine how attribution styles relate to academic performance, student GPAs were obtained for each student at the end of his or her freshman year. In addition, in order to examine student passivity/activity, a measure of the number of trips each student took to the advising center was collected. Results of this study indicated that students whose attribution styles included internal, stable, and global causes (negative attribution styles) for bad events had lower GPAs in their college courses as compared to students who reported external, unstable, and specific causes. This occurred even when students' verbal and quantitative scores on the SAT were held constant. Therefore, attribution style was related to grades in college freshmen.

Another study reported similar results with college students with disabilities. This study, once again, measured college students' attributions and found that negative or pessimistic attribution styles related to lower GPAs (Martinez \& Sewell, 2000). 
Participants consisted of 38 students with physical disabilities and 32 students without physical disabilities, who were matched on the basis of gender and age. Attributions were measured by using the Academic Attribution Style Questionnaire (Peterson \& Barrett, 1987). In order to meet the needs of students with disabilities, several formats were used so that all participants could successfully complete the questionnaires. The various formats included the following: (a) three participants used large print text, (b) two participants listened to an audio-recorded version of questionnaire, (c) one participant responded via audiocassette, and (d) one returned responses in a Braille format. Other participants may have utilized a reader, a scribe, or both. A hierarchical multiple regression analysis was used to examine the relationship between explanatory style (independent variable) and college performance as defined by GPA (dependent variable). In addition, another hierarchical multiple regression analysis was conducted in order to identify if explanatory style (attributions) was a good predictor of college performance as defined by GPA. This study found that explanatory style (attributions) related to GPA, regardless of the presence or absence of a physical disability. In general, students with pessimistic explanatory styles had lower GPAs. This study also found that the more pessimistic explanatory style an individual held, the less likely he or she felt that his or her academic goals could be accomplished.

One possible explanation for lower GPAs within this population may be due to the fact that individuals with pessimistic attribution styles decrease their effort because they do not feel that they have control over their academic performance. As a result, they exhibit behaviors that have a negative impact on their GPAs. Brownlow and Reasinger (2001) found that undergraduate students who attributed successes to factors outside of 
their control, such as luck and context, also were defined as high academic procrastinators. In contrast, undergraduate students who attributed success to effort, which is within their control, did not exhibit as much academic procrastination.

Research also has identified gender differences in attribution styles. Beyer (1998) conducted a study on 246 (156 females, 90 males) undergraduate students enrolled in a general psychology course at a university in the Midwest. Students who participated in the study received course credit. The majority of students were freshmen. Participants were asked to imagine having received either an $\mathrm{A}$ or an $\mathrm{F}$ in a required course. Courses and course numbers presented in the scenario represented actual courses taught at the university. After reading this scenario, participants were supplied with the list of potential causes for an A (F). Students checked each cause that applied, and then rank ordered the importance of the causes. Causes were ranked on a scale of 1 (very important) to 5 (very unimportant). Results of this research indicated that females compared to males attributed success to effort attributions ("paid attention" and "studied"), whereas males used more ability attributions ("good in the subject” and "smart") than females for successful outcomes. This finding was particularly apparent for masculine subject matter. Females also made a greater number of ability attributions to failure for an $\mathrm{F}$ than did males. This reveals a more self-enhancing pattern of causal attributions for males. Males shield their self-confidence when they fail by blaming a poor academic performance on an unstable cause that can be changed in the future. In contrast, females attribute failure to stable causes that they are incapable of changing. With that said, there are more similarities in females' and males' attribution styles than differences. Both genders believed that studying and paying attention are the most vital 
causes of success, whereas luck is seen as having little impact on success (refer to Figure 2 for a description of the attribution studies mentioned in this section). 
Figure 2

Attribution Style and Academic Achievement: Summary of Findings

\begin{tabular}{|c|c|}
\hline $\begin{array}{l}\text { Peterson \& Barrett (1987) } \\
87 \text { freshman students ( } 28 \text { males and } 59 \\
\text { females) attending Virginia Tech }\end{array}$ & $\begin{array}{l}\text { Students whose attribution styles included } \\
\text { internal, stable, and global causes (negative } \\
\text { attribution styles for failure events) for bad } \\
\text { events had lower GPAs in their college } \\
\text { courses as compared to students who } \\
\text { reported external, unstable, and specific } \\
\text { causes (positive attribution styles for } \\
\text { failure events). }\end{array}$ \\
\hline $\begin{array}{l}\text { Beyer (1998) } \\
246 \text { (156 females, } 90 \text { males) undergraduate } \\
\text { students }\end{array}$ & $\begin{array}{l}\text { Females attributed success to effort } \\
\text { attributions ("paid attention" and } \\
\text { "studied"), whereas males used more } \\
\text { ability attributions ("good in the subject" } \\
\text { and "smart”) than females for successful } \\
\text { outcomes. Females also made a greater } \\
\text { number of ability attributions to failure for } \\
\text { an F than did males. }\end{array}$ \\
\hline $\begin{array}{l}\text { Martinez \& Sewell, (2000) } \\
38 \text { students with physical disabilities and } \\
32 \text { students without physical disabilities }\end{array}$ & $\begin{array}{l}\text { Explanatory style (attributions) related to } \\
\text { GPA, regardless of the presence or absence } \\
\text { of a physical disability. Students with } \\
\text { pessimistic explanatory styles had lower } \\
\text { GPAs. }\end{array}$ \\
\hline $\begin{array}{l}\text { Brownlow \& Reasinger (2001) } \\
96 \text { undergraduate students ( } 48 \text { men, } 48 \\
\text { women; distributed among college class) }\end{array}$ & $\begin{array}{l}\text { Undergraduate students who attributed } \\
\text { successes to factors outside of their control, } \\
\text { such as luck and context, were high } \\
\text { academic procrastinators, while } \\
\text { undergraduate students who attributed } \\
\text { success to effort, which is within their } \\
\text { control, did not exhibit as much academic } \\
\text { procrastination. }\end{array}$ \\
\hline
\end{tabular}




\section{Attribution Training Studies}

Since prior research has determined that certain attribution styles are more beneficial to academic success, encouraging more positive attribution styles in students may be a good way to help motivate struggling students. In order to accomplish this goal, attribution-training programs have been developed in order to change negative attribution styles so that they are more positive in terms of their impact on student achievement.

The vast majority of attribution training programs have been conducted with children. Although these studies are not necessarily generalizable to university students, it is still helpful to be aware of the results that have occurred as a result of attribution training programs with children. Robertson's (2000, p. 132) review of research on attribution training concluded that "attribution training can be applied to classroom settings to assist 'at risk' children with poor attributional styles." Therefore, it is possible that attribution training programs may also be beneficial to "at risk" college students. Robertson (2000) reviewed the research of 20 attribution-training studies that were conducted on school-aged children, most of which exhibited academic problems. She found that although some of the studies observed mixed results, the majority of the studies demonstrated success. Results of specific studies involving attribution training are provided below.

Some of this attribution-training research has focused on providing effort attributions for both success and failure (Chapin \& Dyck, 1976; Craske, 1985; Dweck, 1975; Fowler \& Peterson, 1981), while other studies provided students with ability attributions for success and effort attributions for failure (Craven, Marsh, \& Debus, 1991; 
Yasutake, Bryan, and Dohrn, 1996). For instance, Craske (1985) examined the effect of attribution training on persistence while learned helpless students worked on 15 unsolvable puzzles. Learned helpless students, as defined in this context, are those students who feel that they will fail regardless of how much effort they expend with regards to the task at hand. Researchers timed individual students while they worked on these unsolvable puzzles. The study operationally defined and measured persistence (or lack thereof) in terms of the number of minutes each child worked on the puzzles. The longer each student worked, the more persistent that child was considered to be, as determined by the researchers. In addition, a series of solvable puzzles was administered. When students failed, a red light lit up, and they were told their failure was due to lack of effort. When students succeeded, a green light lit up, and they were told that their success was a result of trying hard. Therefore, both successes and failures were attributed to effort. This study revealed that when attributions of failure are attributed to a lack of effort, students exhibit higher levels of persistence. The increase in persistence was higher for females as compared to males. This study suggests that attribution training may be helpful for increasing persistence in learned helpless students, particularly for females. In contrast, Yasutake, Bryan, and Dohrn (1996) completed attribution training students with learning disabilities who served as either tutors or tutees. The tutors were trained to give attributions to the tutees based on their performance on math, spelling, or vocabulary tasks. When tutees succeeded, tutors provided tutees with attributions to either ability or effort. When tutees failed, they were provided with effort or strategy attributions. This study improved both tutor and tutee perceived competence. The attribution of success to ability is believed to be better for self-concept because the 
importance of ability increases in adolescence (Little, Stetsenko, \& Maier, 1999). Most children would rather attribute failure due to lack of effort than lack of ability because it is less damaging to their self-concept (Weiner, 1994). In contrast, when children succeed, they would prefer to believe that their success is a result of ability rather than effort because they like to feel that they achieved because they are "smart" (Nicholls, 1976). Therefore, in order to increase both self-concept and motivation to work hard, it is best to make attributions to both ability (success) and effort (failure) since children take pride in both of these attributes (Weiner, 1994a).

As stated earlier, the majority of attribution-training studies have been conducted on children, although the few studies conducted with college students have produced promising outcomes. A recent study by Holschuh, Nist, and Olejnik (2001) used scenarios in which a fictional student named Kate or Robert attributed a failure in biology to either lack of ability, lack of effort, or lack of strategy use. The purpose of the study was to see how attributions influenced perceptions of future goal setting and emotional responses to failure. Researchers were particularly interested in responses to scenarios that attributed failure to lack of strategy use. Researchers also were interested in identifying gender response patterns. Twelve response patterns were analyzed using a 3 (attribution: ability, effort, strategies) $\times 2$ (scenario, gender) $\times 2$ (respondent, gender) factorial design (Holschuh, Nist, \& Olejnik, 2001)

Holschuh, Nist, and Olejnik’s (2001) study included a total of 488 students. These students volunteered for the study and each student was awarded 15 points toward their grade. Participants included 183 males and 305 females. Most of these students were freshman and sophomores, all of which were enrolled in an introductory biology 
course. Before taking the final exam in BIO 103, all students randomly received one scenario in which a college student (Kate or Robert) discussed their own attributions to failure in an introductory college biology course that they had previously taken. These rationales included an explanation of what caused their failure in this course. The student in each scenario attributed failure to either ability, effort, or learning strategies. After reading the scenarios, students responded to four statements that focused on Kate or Robert's future behaviors and goals. Then, students responded to an additional four statements, which focused on Kate or Robert's emotional responses related to their failure in biology.

Results of this study (Holschuh, Nist, \& Olejnik, 2001) indicated that students consistently believed that Kate (Robert) could modify behaviors or meet their academic goals in biology when attributions were made to controllable factors including either strategies or effort. Participants perceived that Kate (Robert) would experience the most difficulty meeting future goals when attributions were made to ability, which is a relatively uncontrollable attribution. Based on this research, it is likely that when failure is due to a stable, uncontrollable attribute such as ability, it is likely that students will set lower goals in the future. In contrast, when students perceive failure as being the result of unstable and controllable attributions, such as lack of sufficient effort or strategy use, students are more likely to modify future behaviors in order to meet future goals. This study also identified that female participants believed more strongly than did males that Kate (Robert) would be able to reach future goals and be able to make an $A$ in the course the second time around, regardless of the attribution. This finding is consistent with Wilson and Linville’s (1985) study described below, which found that females 
experience less or no change following attribution training because females believe that grades will improve in the future, even prior to attribution training.

Finally, Holschuh, Nist, and Olejnik (2001) measured four emotional responses (sadness, shame, guilt, and anger) on a six-point Likert scale ( $1=$ strongly disagree; $6=$ strongly agree) and found that participants consistently had the strongest response when the attribution was to poor effort and the weakest emotional response when the attribution was to inappropriate strategy use in biology. Ability consistently fell between attributions to effort and strategies. This is not consistent with Weiner's (1994a) study, which found that students typically feel guilt and regret in response to lack of effort and feel shame and embarrassment in response to lack of ability. However, it is important to note that effort and ability were not singled out for measurement purposes, as in Weiner's (1994b) study.

\section{Video-Based Attribution Training Studies}

Studies involving the use of videotapes to provide attribution training have resulted in promising outcomes. Wilson and Linville $(1982,1985)$ conducted two research studies that demonstrated the effectiveness of video-based attribution training with college students. The first study conducted by Wilson and Linville (1982) was designed to increase the academic performance of college students by suggesting that failure is a result of unstable, and therefore changeable, causes. This study included a sample of 71 second-semester freshmen (22 males and 49 females). This sample of students was obtained by administering a questionnaire to 200 students from Duke University’s psychology department subject pool. Students completed a questionnaire that was specifically designed to look at selection criteria. The questionnaire included 
items which obtained the following student self-report information: (a) their previous semester GPA, (b) how they thought they compared to their peers intellectually, (c) the extent to which they worried about their academic performance, and (d) whether or not they think they could have performed better in the previous semester. In order to be selected for the study, student had to meet the following four criteria: (a) they worried about their academic performance more than their peers, as identified by the median score on the questionnaire, (b) first semester GPA was at or below 3.5, (c) they reported not doing as well as they could have, and (d) they did not report that they compared much better intellectually than their average peers. The 71 second-semester freshmen (22 males and 49 females) mentioned above met the four criteria. Only 40 of these students, however, were contacted to participate in the study. Students were unaware of the purpose of the study. The experimenter told students that she wanted them to become familiar with the types of survey questions that upperclassman respond to as well as results of these surveys.

Once participants were selected, sets of three males and seven females were randomly assigned to one of four conditions, (Wilson \& Linville, 1982). Half of the participants were randomly assigned to the GPA treatment condition. The other half of the students were assigned to the no-information condition. The treatment condition involved a one-time manipulation. Students who received the treatment read survey results of upperclassmen stating how GPAs improved following their freshman year. Participants in the treatment group also viewed videotaped interviews of upperclassmen. In these videos, upperclassmen stated their GPAs for the first semester of their freshman year, the second semester of their freshman year, and their GPA for their most recent 
semester of college (all had progressively increased). The videotapes included two males and two females, two of which were juniors, and the remaining two were seniors (four total). The control group received neither the survey results of upperclassmen stating how GPAs improved following their freshman year, or the upperclassmen videos which contained information about upperclassmen GPAs for the first semester of their freshman year, the second semester of their freshman year, and their GPA for their most recent semester of college above (all had progressively increased). Half of each of the GPA and no-information conditions were assigned to the reasons analysis condition. Participants in the GPA condition were asked to state why they think the described students increased their grades in freshman to upper-class years. Participants in the no-information condition were asked to write about a filler question.

Dependent measures included a measure of both short-term (at beginning and one week later) and long-term variables (Wilson \& Linville, 1982). Short-term measures included performance on GRE study book questions and anagram questions, questionnaires measuring attitudes toward performance, expectations about future success, and mood scales, (Wilson \& Linville, 1982). Long-term measures included GPAs for five semesters following the study and a comparison of control and treatment group participants in order to identify which participants left college one year following study.

Results of this study indicated that participants in the treatment group, who received the information about unstable causes of failure, performed better on both shortterm and long-term measures of academic performance (GRE questions and subsequent GPAs), (Wilson \& Linville, 1982). In addition, participants in the treatment condition 
reported higher expectations for future success. Although behavioral measures of academic performance were promising, self-report measures showed little impact. Selfreport measures did not correlate with performance measures. When comparing selfreport and performance measures, it is important to note that self-report measures are not as reliable because student performance is an observable dependent measure whereas self-report measures are perceptions that may or may not be consistent with a particular student's actions. Students may not report behavior accurately for many reasons. Students may be in a hurry and mark answers without actually reading the questions, they may make inaccurate self-reports in order to make themselves appear in a positive (negative) light, or they may make responses based on their perceptions of what the researcher desires to conclude. Therefore, it is possible to change behavior but not selfreport measures of attributions even when applying the same treatment condition. The results of this study (Wilson and Linville, 1982) suggest that videotaped interviews with upperclassmen, who report temporary problems as freshman, could be shown as part of an attempt to help struggling freshmen improve their academic performance.

In order to further strengthen the results of the above findings, Wilson and Linville (1985) followed up their previous study (Wilson \& Linville, 1982) with two replication studies. The first study was an exact replication of the above study with the exception of a few changes. First, students attended the University of Virginia. There were 25 participants in the treatment group and 14 students in the control group. They were included in the study if their GPA was 3.0 or lower as opposed to 3.5 or lower. Second, two different experimenters were used. One, who was blind to the condition, implemented the dependent variables, and another experimenter implemented the 
independent variables. Unlike the previous study (Wilson \& Linville, 1982), students did not return a week later and complete the dependent measures again. Finally, two treatment groups were utilized. The first was identical to the previous study (Wilson \& Linville, 1982), but the second treatment group was told that grades were low in the freshman years, but participants were not given information indicating that grades improved in the students' upperclassmen years.

In the second replication, there were 20 participants (five males and 15 females) in the control group and 21 participants (five males and 16 females) assigned to the treatment group (Wilson \& Linville, 1985). Participants included first-semester as opposed to second-semester freshman. Similar to the two previous studies, students were also unaware of the purpose of the study, but in this study, the cover story had changed. Students were told that the study, in which they were participating was part of a larger study designed to give high school students information about what to expect in their first year of college. As part of the cover story, students completed a questionnaire that supposedly identified differences between college and high school. Students read similar statistic information and viewed videotapes, but this time, they did so in groups of four to six. In addition to the statistic and videotape viewing, this study had participants in the treatment group compose an essay explaining why their grades were not as high as they would have liked. Their responses were coded by using Russell’s (1982) Causal Dimension Scale. An additional modification of this study included a larger sample of items from the Graduate Record Exam in order to increase the reliability of this measure. In this study, students answered 13 comprehension questions in response to two paragraphs, in comparison to the six questions in response to one paragraph in replication 
one and the first study (Wilson \& Linville, 1982).

Results of the Wilson and Linville (1982) study were similar to the current study (Wilson \& Linville, 1985), with the exception of some gender differences. The shortterm performance measure on the Graduate Record Exam sample items revealed that males in the treatment condition performed better on these questions than males in the control condition. However, the performance of females in the treatment condition did not differ from controls. On the long-term performance measure, measuring subsequent GPAs, participants in the treatment condition had higher subsequent GPAs as compared to the control participants. Although this finding was true for both males and females, the effect was larger for males. Authors of this study suggested that differences between males and females may be due to the fact that females were already aware of the fact that GPAs increase following the freshman year. Therefore, the treatment condition was unsuccessful because females were already aware of the information presented in the treatment condition. Further attribution-based research studies on gender differences are needed in order to help researchers better understand differences between males' versus females’ prior perceptions of college performance. Future studies will help identify to what extent Wilson and Linville’s (1985) hypothesis about girls’ perceptions is accurate.

Perry and Penner (1990) also conducted a study involving video-based attribution training with college students. First-year college students (198) viewed a videotape of a college professor that stressed the importance of attributing successes and failures to both ability and effort. A control group received no training. Following training, students viewed a 25-minute videotaped lecture, and study materials were distributed. One-week post training, students returned to class and took a 30-item achievement test on the 
videotaped lecture content. Students also completed a 10-item test on the homework assignment (study materials). Results indicated that attribution training increased performance on both the lecture and homework tests for students with an external locus of control, but not for students with an internal locus of control.

A similar study involving two separate experiments was completed with at-risk college students, where attribution training was combined with effective teaching (Menec, Perry, Struthers, Schonwetter, Hechter, \& Eicholz, 1994). In Experiment One, 156 (77 female, 78 male, and one unreported) introductory psychology students took a 24-item achievement test designed to differentiate between failure and success students. Failure students on that achievement test were classified as at-risk. After being categorized as failure or success students, students viewed either no, one, or two attributional training videotapes. Multiple sessions were delivered at one-week intervals. Attributional training videos were both eight minutes in length, and a male graduate student explained an incident where he or a friend had failed on a task. This graduate student explained how he or his friend improved performance by increasing effort and using more effective study strategies. Following the training video, students viewed a 25-minute lecture with either a high expressive or a low expressive instructor. Students were placed into groups in which they either received sessions. Dependent measures included a (1) 30-item multiple-choice test based on the videotaped lecture, (2) the psychology class' regular test that followed the attribution training, and (3) the final grade in the psychology class.

Experiment Two involved 257 (122 female,129 male, and 6 unreported) introductory psychology students. Basic procedures were as in Experiment One 
including, (1) video-taped lectures with high and low expressiveness, (2) video-taped attribution training, and (3) failure versus success students. However in this experiment, students were also categorized based on locus of control. Students also took a GRE-type question test and only students who scored below the median on this test were included in the study. Two additional retraining tapes (six minutes in length) were added in which two senior students (one male and one female) discussed various failure experiences, attributing failure to lack of effort and inadequate strategies. A psychology professor summarized important points of their discussion.

Results of the two studies indicated that attributional retraining enhanced achievement on a lecture-based achievement test, only when combined with a lecture that contained a highly expressive instructor. In addition, only those students who had previously performed poorly (Experiment One) and low-achieving externals (Experiment Two) improved achievement on this task (refer to Figure 3 for a summary of attribution training studies).

Attribution training programs have produced successful outcomes with both school-aged and undergraduate students (refer to Figure 3). Attribution training programs have helped school-aged students and college students better deal with failures. These training programs helped students by teaching them to attribute failures to things in which they had control over, such as increasing effort and modifying study strategies. 
Figure 3

Attribution Training Studies: Summary of Findings

\begin{tabular}{|c|c|}
\hline Studies With Children & \\
\hline $\begin{array}{l}\text { Craske (1985) } \\
\text { Students with learned helplessness }\end{array}$ & $\begin{array}{l}\text { This study revealed that when attributions } \\
\text { of failure are attributed to a lack of effort, } \\
\text { students exhibit higher levels of } \\
\text { persistence. The increase in persistence } \\
\text { was higher for females as compared to } \\
\text { males. }\end{array}$ \\
\hline $\begin{array}{l}\text { Yasutake, Bryan, \& Dohrn (1996) } \\
\text { Students with learning disabilities who } \\
\text { served as either tutors or tutees }\end{array}$ & $\begin{array}{l}\text { This study improved both tutor and tutee } \\
\text { perceived competence when attributions for } \\
\text { successful outcomes were made to effort or } \\
\text { ability and when attributions for failure } \\
\text { were made to effort or lack of strategy use. }\end{array}$ \\
\hline $\begin{array}{l}\text { Robertson's (2000) } \\
\text { A review of } 20 \text { studies involving } \\
\text { attribution training with school-aged } \\
\text { children }\end{array}$ & $\begin{array}{l}\text { Robertson's (2000, p.132) review of } \\
\text { research on attribution training concluded } \\
\text { that “attribution training can be applied to } \\
\text { classroom settings to assist 'at risk' } \\
\text { children with poor attributional styles.” }\end{array}$ \\
\hline
\end{tabular}


Figure 3

Attribution Training Studies: Summary of Findings

\begin{tabular}{|c|c|}
\hline Studies with & \\
\hline $\begin{array}{l}\text { Wilson \& Linville (1982) } \\
\text { Video-Based } \\
40 \text { second-semester freshmen }\end{array}$ & $\begin{array}{l}\text { Participants in the treatment group, who } \\
\text { received the information about unstable } \\
\text { (lack of effort) causes of failure, performed } \\
\text { better on both short-term and long-term } \\
\text { measures of academic performance (GRE } \\
\text { questions and subsequent GPAs). }\end{array}$ \\
\hline $\begin{array}{l}\text { Wilson \& Linville (1985) } \\
\text { Video-Based } \\
1^{\text {st }} \text { replication - } 39 \text { second-semester } \\
\text { freshmen } \\
2^{\text {nd }} \text { replication - } 41 \text { first-semester freshmen. }\end{array}$ & $\begin{array}{l}\text { Graduate Record Exam sample items } \\
\text { revealed that males in the treatment } \\
\text { condition performed better on these } \\
\text { questions than males in the control } \\
\text { condition. Performance of females in the } \\
\text { treatment condition did not differ from } \\
\text { controls. } \\
\text { GPAs were better for treatment group as } \\
\text { compared to controls. }\end{array}$ \\
\hline $\begin{array}{l}\text { Holschuh, Nist, \& Olejnik (2001) } \\
488 \text { undergraduate students }\end{array}$ & $\begin{array}{l}\text { Participants believed that behaviors could } \\
\text { be modified to academic goals in biology } \\
\text { when attributions were made to } \\
\text { controllable factors (strategies or effort). } \\
\text { Participants perceived that it is difficult to } \\
\text { achieve future goals when attributions were } \\
\text { made to ability (uncontrollable attribution). }\end{array}$ \\
\hline $\begin{array}{l}\text { Perry and Penner (1990) } \\
\text { Video-Based } \\
198 \text { first-year college students }\end{array}$ & $\begin{array}{l}\text { Results indicated that attribution } \\
\text { training increased performance on both the } \\
\text { lecture and homework tests for students } \\
\text { with an external locus of control, but not } \\
\text { for students with an internal locus of } \\
\text { control. }\end{array}$ \\
\hline $\begin{array}{l}\text { Menec, Perry, Struthers, Schonwetter, } \\
\text { Hechter, and Eicholz (1994) } \\
\text { Video-Based } \\
\begin{array}{l}\text { Experiment One - } 156 \text { ( } 77 \text { female and } 78 \\
\text { male) introductory psychology students }\end{array} \\
\begin{array}{l}\text { Experiement Two - } 257 \text { (122 female and } \\
129 \text { male) introductory psychology } \\
\text { students }\end{array}\end{array}$ & $\begin{array}{l}\text { Results of the two studies indicated that } \\
\text { attributional retraining enhanced } \\
\text { achievement on a lecture-based } \\
\text { achievement test, only when combined } \\
\text { with a lecture that contained a highly } \\
\text { expressive instructor. In addition, only } \\
\text { those students who had previously } \\
\text { performed poorly (Experiment One) and } \\
\text { low-achieving externals (Experiment Two) } \\
\text { improved achievement on this task. }\end{array}$ \\
\hline
\end{tabular}


The studies with school-aged children, as identified above, helped students to increase persistence and develop more positive perceptions about academic achievement. Similarly attribution training programs with college students were successful in helping students attain more positive perceptions pertaining to future academic goals and increasing both short and long-term measures of academic achievement (GRE practice sample items and GPAs).

The present dissertation study will focus on examining differences on academic performance (homework completion rate and GRE practice score) for students who receive both live-testimonial based attribution training and video-based attribution training. Males and females will be analyzed separately on performance measures (homework completion rate and GRE practice score) in order to see if the above results are replicable with further modifications. This study will help researchers further determine the effectiveness of attribution training that is carried out in a single session. 


\section{CHAPTER 2}

Method

\section{Participants}

The sample consisted of undergraduate freshman students $(\mathrm{N}=93)$ enrolled in a study strategies course, during the fall semester, at a mid-sized university in the Northeastern region of the United States. Most of the participants were in the course because they were considered to be academically at-risk. For first-semester freshman, there were two main reasons that students were considered to be at-risk; (a) they received an ACT composite score of 18 or below (SAT score of 800 or less), and/or (b) they had a high school grade point average of 2.5 or below. Many of the students were advised to enroll in the course by either their primary advisor or the student advising center. Participants consisted of all students who were present during the class meetings in which the study took place. However, this research analyzed differences between participants who had a composite score of 18 or above on the ACT or an 880 or above on the SAT and those students who did not. These numbers were derived by obtaining the median split of the participants’ ACT (median =17) or SAT (median = 870) scores. Participants who had an ACT or SAT score at or below the median were placed in the low ACT/SAT category while all other students were placed in the high ACT/SAT category. Comparisons between the two groups were made because the most recent meta-analysis on attribution studies concluded that attribution training works best with students who have the ability to do well academically but are struggling with academics due to insufficient effort or lack of proper study strategies (Robertson, 2000). 


\section{Study Strategies Course}

Six sections of the study strategies course were included in the study. This course is a three-hour course that meets three times a week and is designed to help students learn how to use effective study strategies, manage their time, and increase their organizational skills. It is a highly structured course, and lack of student attendance can be detrimental to each student's performance in the class. Students receive a letter grade for the course and automatically fail the course after ten unexcused absences. Homework is also a large portion of each student's overall grade. Students have at least one (usually multiple) homework assignment due each class meeting. Multiple assignments are included in the course so that students have many opportunities to earn points to succeed.

A sample of convenience was used for this study. Permission was obtained from the director of the study strategies course program. Permission also was obtained from the students, individual instructors of each course section, and the Institutional Review Board for the Protection of Human Subjects at the university where the study was conducted.

Since many of the students enrolled in this course were considered to be academically at-risk, an intent of the training was to facilitate more positive attribution or explanatory styles which may increase students' effort and improve their undergraduate GPAs. A significant increase in GPAs may help to remove applicable students from an academic probation status. Earlier research suggests that pessimistic attribution styles could be a risk factor contributing to declined academic performance in college students (e.g., Martinez \& Sewell, 2000). Furthermore video-based attribution training studies, designed to alter attributions and improve performance, have been successful in 
increasing college students' GPAs (Wilson \& Linville, 1982; 1985). Based on the results of attribution training programs conducted with both children and undergraduate students (Carr \& Borkowski, 1989; Craske, 1985; Peterson \& Barrett, 1987), it seems that negative attributions can cause poor academic performance, since modeling positive attribution styles leads to improved academic performance. Evidence of this causal relationship was made particularly evident in an attribution training study by Carr and Borkowski (1989), which concluded that enhancing positive attributional beliefs was the critical element in increasing reading grades for children in the third, fourth, and fifth grades. Further experimental-based research is needed in order to strengthen evidence for a causal relationship between attribution styles and academic achievement.

\section{Cover Letter}

A cover letter was provided to each student prior to the collection of data. The cover letter was written in accordance with the standards set by the Institutional Review Board for the Protection of Human Subjects (see Appendix A). This letter briefly explained the purpose of the study, contact persons, confidentiality, and voluntary participation. In order to emphasize that each participant's anonymity was protected, students were informed that no names or other identifying information would be revealed in any of the documentation that may accompany this study. Participants also were given the researcher's name and address, so that on completion of this study, participants can obtain results.

Procedure

Participants included students in six of the ten study strategies sections. The researcher chose the six study strategies sections that had the highest enrollments of 
students. Data were collected in one of six settings. Settings were counterbalanced based on time (beginning or end of semester), gender of script reader (male or female), and type of attribution training (video-based training, testimonial-based training, or control). Homework completion rate and GRE practice question scores served as dependent measures and were of particular interest because both measure academic performance. Homework completion rates were chosen as opposed to GPAs because many of the study strategies students are first-semester freshman and have no previous college GPAs to serve as a pre-attribution training comparison. Homework completion rate, in particular, is a measure of effort because students have to take the time to complete their assignments in order to complete a percentage of their homework. In addition, Wilson and Linville (1982) found GRE practice questions to be a good measure of academic performance following attribution training. Wilson and Linville (1982) stated that performance measures (GRE practice score and GPAs) showed improvement following attribution training even when students did not report an actual cognitive change in their attribution style. Both dependent measures chosen for this study are measures of performance because Wilson and Linville (1982) concluded that attribution training appears to have a greater impact on actual behaviors (GRE practice scores and GPAs) as opposed to cognitions (changes in attributional style).

Homework completion rate and performance on five graduate record exam (GRE) sample questions were collected for each participant one-week prior to and one week following attribution training. The primary researcher administered the GRE sample questions at the beginning of class, one week prior to and one week following the attribution training. The primary researcher scored each pre and post test for the GRE 
sample questions and obtained a percentage of questions correct for each student.

For the homework completion rates, the teaching assistants in each of the six sections received a one-page handout including the list of all homework assignments for the week prior to (Week 5or Week 11) and the week following (Week 7 or Week 13) attribution training. The teaching assistants documented whether or not the students turned in each of the assignments by marking a zero or a one by each homework assignment. Students received half credit for turning in a portion of their homework assignments. The primary researcher calculated percentages of homework completed for every participant. Demographic information and ACT/SAT scores for participants were obtained from the university upon completion of the fall semester.

\section{Training Video-Based and Live-Testimonial Script Readers}

Two junior-level pre-service teachers were chosen to be script readers for this attribution trainings. Each script reader was required to memorize a prepared script (see Appendix B) that expressed his or her struggles in English 101. The script described how he or she overcame his or her struggles and succeeded in this class. Both script readers were given the script to look over before agreeing to participate in the study. Once script readers made their decision, they signed an informed consent, which signified their voluntary agreement to read scripts for the purposes of this study. This consent form also gave the researcher permission to allow each script reader's image to be portrayed on screen via videotape.

After informed consent was signed and collected, script readers were instructed to take the script home and memorize the script over the course of three weeks. They were instructed to practice and present the script as if it were their own personal story. Script 
readers came in for videotaping. Prior to videotaping the script readers, were given a chance to practice the script in front of the primary researcher and the director of the study strategies course. When script readers were video-taped, they were provided with the script on overhead, so that they had something to fall back on if they forgot a portion of their script. Overheads also were provided in order to insure that both script readers read the same script verbatim, therefore providing consistency within the study. They practiced the script two times in front of the primary researcher and the director of the study strategies course, before being videotaped in order to provide script readers with feedback. After this entire process was complete, the script readers were videotaped. The male came in for videotaping during a second session due to problems (long pauses when reading script) with the first presentation taping. He practiced the script once and was then taped on two occasions while reading the script. Each video (female at 6 weeks and male at 12 weeks) was shown to students enrolled in two different sections of the Fall 2003 section of the study strategies course. At both the 6-week and 12-week showing of the video, the primary researcher played the video approximately ten minutes after the starting time of each class. After the video was shown, the primary researcher left the class, and there was no further discussion of the video.

The same male (6 weeks) and female (12 weeks) script readers presented this same information in a live-testimonial in front two separate sections of the Fall 2003 study strategies class, during a regularly scheduled class meeting for the study strategies course. The script readers practiced their live testimonial in front of the primary researcher one-week prior to presenting the testimonial to the study strategies course. Both script readers practiced the script once, received feedback, and then practiced again 
until the suggested changes were made.

Both live-testimonials took place approximately ten minutes after the regularly scheduled time for the class. After the live-testimonial had been presented, the primary researcher informed the class that they were required to ask the script reader at least one question about his or her study habits. During the sixth week of the first semester, with the male presenter, three questions were asked. The questions included: "Who did you have for English 101?”: “Where is the writing center located?”; and "How much time did you spend going out to bars and hanging out with friends?” During the twelfth week in the first semester, in which the female presented, two questions were asked. The questions were as follows: “How much more time did you spend studying?” and "How much did you decrease going out to bars?”

Two separate sections of the study strategies course served as control groups. One section was a control group during the 6-week attribution training, and the other section was a control group during the 12-week attribution training. The two control groups did not watch the video and were not presented with a live-testimonial. The GRE practice score and homework completion rates were collected at Week five of the semester and again at Week seven of the semester in three sections (live, video, and control) of the study strategies course. GRE practice score and homework completion rates also were collected again at Weeks 11 and 13 of the semester for three separate sections (live, video, and control) of the study strategies course.

Research Questions

Research Question 1. Does Presentation Mode (video, live, or control) make a difference on GRE practice score or homework completion rate? A one-way analysis of 
variance (ANOVA) was used with each of the two dependent variables to answer this research question. Presentation Mode (video, live, or control) is a between-subjects independent variable. Change Score (post minus pre) for homework completion rate was one dependent variable. Change Score (post minus pre) for GRE practice score was the second dependent variable. See Table 1 for a summary of independent and dependent variables.

Ha 1: Performance on GRE practice score and homework completion rate is better after students receive video-based or live-testimonial attribution training than compared to students who receive neither (control).

Ho 1: Performance on GRE practice score and homework completion rate is not better after students receive video-based or live-testimonial attribution training as compared to students who receive neither (control).

Research Question 2. Does Time of Semester (beginning versus end) make a difference on GRE practice score or homework completion rate? A one-way ANOVA was used with each of the two dependent variables to answer this research question. Time of Semester (beginning versus end) is a between-subjects independent variable. Change Score (post minus pre) for homework completion rate was one dependent variable. Change Score (post minus pre) for GRE practice score was the second dependent variable. See Table 1 for a summary of independent and dependent variables.

Ha 2: Performance on GRE practice score and homework completion rate is different when attribution training is conducted at the beginning of the semester as opposed to the end of the semester.

Ho 2: Performance on GRE practice score and homework completion rate is not 
different when attribution training is conducted at the beginning of the semester as opposed to the end of the semester.

Research Question 3. Does the Gender of the Script Reader (male versus female) make a difference on GRE practice score or homework completion rate? A oneway ANOVA was used with each of the two dependent variables to answer this research question. Gender of the Script Reader (male versus female versus no gender) is a between-subjects independent variable. Change Score (post minus pre) for homework completion rate was one dependent variable. Change Score (post minus pre) for GRE practice score was the second dependent variable. See Table 1 for a summary of independent and dependent variables.

Ha 3: Performance on GRE practice score and homework completion rate is different when there is a male script reader as opposed to a female script reader following either video-based and live-testimonial attribution training.

Ho 3: Performance on GRE practice score and homework completion rate is not different when there is a male script reader as opposed to a female script reader following either video-based and live-testimonial attribution training.

Research Question 4. Does the Gender of the Participant (male versus female) make a difference on GRE practice score or homework completion rate? A one-way ANOVA was used with each of the two dependent variables to answer this research question. Gender of the Participant (male versus female) is a between-subjects independent variable. Change Score (post minus pre) for homework completion rate was one dependent variable. Change Score (post minus pre) for GRE practice score was the second dependent variable. See Table 1 for a summary of independent and dependent 
variables.

Ha 4: Performance on GRE practice score and homework completion rate is better for males, but not for females following either video-based and live-testimonial attribution training.

Ho 4: Performance on GRE practice score and homework completion rate is not better for males, but not for females, following either video-based and livetestimonial attribution training.

Research Question 5. Do high (18 or above on ACT and 880 or above on ACT) versus low (17 and below on ACT and 870 or below on SAT) ACT and SAT scores make a difference on GRE practice scores or homework completion rate? A one-way ANOVA was used with each of the two dependent variables to answer this research question. ACT and SAT scores (high versus low) is a between-subjects independent variable. Change Score (post minus pre) for homework completion rate was one dependent variable. Change Score (post minus pre) for GRE practice score was the second dependent variable. See Table 1 for a summary of independent and dependent variables.

Ha 5: Performance on GRE practice score and homework completion rate is different for students with low ACT or SAT scores as opposed to students with high ACT or SAT scores.

Ho 5: Performance on GRE practice score and homework completion rate is not different for students with low ACT or SAT scores as opposed to students with high ACT or SAT scores.

\section{Research Design}

As noted, the between-subjects independent variables were (RQ1) Presentation 
Mode (video, live, or control), (RQ2) Time of Semester (beginning versus end), (RQ3)

Gender of Script Reader (male versus female), (RQ4) Gender of Participant (male versus female), and (RQ5) ACT or SAT scores (high versus low). Change Scores (post minus pre) served as dependent variables for both GRE practice score and homework completion rate. 


\section{Table 1}

Independent and Dependent Variables for the Five Research Questions

Research Questions Independent Variables Dependent Variables

\begin{tabular}{|c|c|c|}
\hline \multirow[t]{4}{*}{ RQ1 } & Presentation Mode & Change Score (Post minus Pre) \\
\hline & 1. Live & 1. Homework Completion Rate \\
\hline & 2. Video & 2. GRE Practice Score \\
\hline & 3. Control & \\
\hline \multirow[t]{3}{*}{ RQ2 } & Time of Semester & Change Score (Post minus Pre) \\
\hline & 1. Beginning & 1. Homework Completion Rate \\
\hline & 2. End & 2. GRE Practice Score \\
\hline \multirow[t]{4}{*}{ RQ3 } & Gender of Script Reader & Change Score (Post minus Pre) \\
\hline & 1. Male & 1. Homework Completion Rate \\
\hline & 2. Female & 2. GRE Practice Score \\
\hline & 3. No Gender & \\
\hline \multirow[t]{3}{*}{ RQ4 } & Gender of Participant & Change Score (Post minus Pre) \\
\hline & 1. Male & 1. Homework Completion Rate \\
\hline & 2. Female & 2. GRE Practice Score \\
\hline \multirow[t]{3}{*}{ RQ5 } & ACT or SAT Score & Change Score (Post minus Pre) \\
\hline & 1. High & 1. Homework Completion Rate \\
\hline & 2. Low & 2. GRE Practice Score \\
\hline
\end{tabular}




\section{CHAPTER 4}

Results

This chapter examines the findings for each of the five research questions. An alpha level of .05 was the significance level in all statistical tests.

Research Question One (RQ1) investigated whether the mode of presentation (live versus video versus control group) made a difference on GRE practice scores or homework completion rates. Using change scores between pretest and posttest (post minus pre) measurements of the dependent criterion variables of GRE practice score and homework completion rate, results for RQ1 were analyzed using a one-way Analysis of Variance (ANOVA), for each of the two dependent variables. No significant difference was identified between modes in relation to GRE practice scores, $F(2,48)=.808, p=$ .452. However, analysis for homework completion rate revealed a trend toward a significant effect for mode of delivery in relation to homework completion rate, $F(2,89)=$ 2.43, $p=.089$. A Tukey post-hoc multiple-comparisons analysis showed that participants receiving the live mode of presentation scored significantly $(\mathrm{p}<.05)$ higher on homework completion rates than the control group. There were no significant differences between participants in the video mode and the other two groups (refer to Table 2 for the Ns, Means, and Standard Deviations). 
Table 2

Mean Change Scores and Standard Deviations for Homework Completion Rate and GRE Practice Score as a Function of Presentation Mode

\begin{tabular}{|c|c|c|c|c|}
\hline \multirow{2}{*}{$\begin{array}{l}\text { Presentation } \\
\text { Mode }\end{array}$} & \multicolumn{2}{|c|}{ Mean Change Scores } & \multicolumn{2}{|c|}{ Standard Deviations } \\
\hline & Homework & GRE & Homework & GRE \\
\hline Live & $9.51(\mathrm{n}=31)$ & $-3.33(\mathrm{n}=18)$ & 25.58 & 30.10 \\
\hline Video & $5.31(n=29)$ & $4.04(n=20)$ & 26.31 & 22.10 \\
\hline Control & $3.72(n=32)$ & $7.69(n=13)$ & 20.23 & 20.88 \\
\hline
\end{tabular}

Note. Means with a minus indicate that students scored lower on the post test than on the pre test.

Research Question Two (RQ2) investigated whether the time of semester (beginning versus end) made a difference on GRE practice scores and/or homework completion rates. Using change scores between pretest and posttest (post minus pre) measurements of the dependent criterion variables of GRE practice score and homework completion rate, results for RQ2 were analyzed using a one-way ANOVA, for each of the two dependent variables. There was no significant effect for time of semester in relation to GRE practice score, $F(1,49)=2.07, p=.16$. However, analysis revealed a significant effect for time of presentation in relation to homework completion rate, $F(1,90)=15.13$, $p<.0001$. The participants who were involved in the study at the beginning of the semester had significantly higher increases in homework completion rate when compared to participants who were involved in the study at the end of the semester (refer to Table 3 for the Ns, Means, and Standard Deviations). 
Table 3

Mean Change Scores and Standard Deviations for Homework Completion Rate and GRE Practice Score as a Function of Time of Semester

\begin{tabular}{lllll}
\hline & \multicolumn{2}{l}{ Mean Change Scores } & & \multicolumn{2}{c}{ Standard Deviations } \\
\cline { 2 - 3 } & & & & \\
$\begin{array}{l}\text { Time of } \\
\text { Semester }\end{array}$ & Homework & GRE & Homework & GRE \\
\hline Beginning & $14.1(\mathrm{n}=40)$ & $-2.14(\mathrm{n}=28)$ & 25.45 & 25.73 \\
End & $-4.52(\mathrm{n}=52)$ & $7.83(\mathrm{n}=23)$ & 20.53 & 23.15 \\
\hline
\end{tabular}

Note. Means with a minus indicate that students scored lower on the post test than on the pre test.

Research Question Three (RQ3) investigated whether the gender of the script reader (male versus female versus neither) made a difference on GRE practice score or homework completion rate. Using change scores between pretest and posttest (post minus pre) measurements of the dependent criterion variables of GRE practice score and homework completion rate, results for RQ3 were analyzed using a one-way ANOVA, for each of the two dependent variables. The "neither" value represented participants in the control group, who had neither the male nor female script reader. This analysis revealed a trend toward a significant effect for gender of the reader in relation to GRE practice score, $F(1,48)=2.48, p=.10$. There was no significant differences between mean scores identified in relation to homework completion rate, $F(2,89)=2.27, p=.11$ (refer to Table 4 for the Ns, Means and Standard Deviations).

A Tukey post-hoc multiple-comparisons analysis found no significant differences for 
gender of the script reader.

Table 4

Mean Change Scores and Standard Deviations for Homework Completion Rate and GRE Practice Score as a Function of Gender of the Script Reader

Mean Change Scores

Standard Deviations

Gender of Script Reader

\section{Homework GRE}

Homework GRE

Male

$8.33(\mathrm{n}=27) \quad 8.89(\mathrm{n}=18)$

23.48

27.63

Female

$6.79(\mathrm{n}=33)-7.01(\mathrm{n}=20)$

27.90

22.73

Neither

$-3.72(\mathrm{n}=32) 7.69(\mathrm{n}=13)$

20.23

20.89

Note. Means with a minus indicate that students scored lower on the post test than on the pre test.

Research Question 4 (RQ4) investigated whether the gender of the participant

(male versus female) made a difference on GRE practice score or homework completion rate. Using change scores between pretest and posttest (post minus pre) measurements of the dependent criterion variables of GRE practice score and homework completion rate, results for RQ4 were analyzed using a one-way ANOVA, for each of the two dependent variables. This analysis revealed no significant effect for gender of the participant in relation to GRE practice scores, $F(1,48)=.223, p=.64$. There was also no significant effect for gender in relation to homework completion rate, $F(1,89)=1.59, p=.21$ (refer to Table 5 for the Ns, Means, and Standard Deviations). 
Table 5

Mean Change Scores and Standard Deviations for Homework Completion Rate and GRE Practice Score as a Function of Gender of the Participant

Mean Change Scores $\quad$ Standard Deviations

Gender of The Participan

Homework GR

Homework GRE

Male

$0.49(\mathrm{n}=47)$

$4.29(n=28)$

22.80

25.74

Female

$6.98(\mathrm{n}=44) \quad 0.91(\mathrm{n}=22)$

26.29

24.28

Note. Means with a minus indicate that students scored lower on the post test than on the pre test.

Research Question 5 (RQ5) investigated whether ACT and SAT scores (high versus low) made a difference on GRE practice scores or homework completion rates. Median scores were obtained for both the ACT and SAT data. All scores above the median were placed in the high ACT/SAT group, while scores at or below the median were placed in the low ACT/SAT group. The median score for ACT was a score of 17, while the median score for the SAT was a score of 870. Using change scores between pretest and posttest (post minus pre) measurements of the dependent criterion variables of GRE practice scores and homework completion rates, results for RQ5 were analyzed using a one-way ANOVA, for each of the two dependent variables. This analysis revealed no significant effect for high or low ACT/SAT scores in relation to GRE practice scores, $F(1,46)=.510, p<.479$. There was also no significant effect for high or low ACT/SAT scores in relation to homework completion rates, $F(1,85)=.036, p=.850$ 
(refer to Table 6 for the Ns, Means, and Standard Deviations).

Table 6

Mean Change Scores and Standard Deviations for Homework Completion Rate and GRE Practice Score as a Function of High or Low ACT/SAT Scores

Mean Change Scores Standard Deviations

ACT/SAT

Scores

Homework GRE

Homework GRE

High

$5.17(\mathrm{n}=34) \quad 5.26(\mathrm{n}=19)$

24.10

28.16

Low

$4.18(\mathrm{n}=53) \quad 0.01(\mathrm{n}=29)$

23.74

22.68

Note. Means with a minus indicate that students scored lower on the post test than on the pre test.

The researcher also conducted an analysis by omitting the middle scores in order to strengthen the statistical analysis. ACT or SAT (high versus low) was divided according to each individual participant's score on either the ACT or SAT, and each participant was placed in either the high or low condition on the basis of his or her score. Students who obtained a score of 13 or below on the ACT were placed in the low category as were students who obtained an SAT score below 800. Students in the high ACT/SAT group were those students who received a score of 27 or higher on the ACT or a score of 1200 or higher on the SAT. Students who received scores between 13 and 27 on ACTs or 801 and 1199 on SATs were not included in order to differentiate between high and low scores on ACTs and SATs.

Few participants fit the high and low categories. Once the middle was omitted 
there were only seven participants who met the low ACT or SAT criteria and one student who met the high ACT or SAT criteria. Both high and low ACT or SAT scores represented only eight percent of the total sample size. Due to a limited sample, the statistical analysis proposed would not have provided beneficial information, due to lack of homogeneity of variance in sample sizes. As a result, these data were analyzed in a qualitative fashion. Raw data indicated that three of the seven students in the low ACT/SAT category increased their percentage of homework completion rates, while three out of five students decreased their percentage of homework completion rates. The remaining student neither increased nor decreased homework completion rate. When GRE practice score was analyzed for students in the low ACT/SAT group, raw data indicated that two students increased their percentage on GRE practice score, one student decreased his or her percentage on GRE practice score, and the remaining two students neither increased nor decreased their percentages. For the one student in the high SAT/ACT group, raw data indicated that this individual had increased percentages on both homework completion rate and GRE practice score. 


\section{CHAPTER 5}

\section{Discussion}

The main purpose of this study was to see whether video or live-based attribution training was effective in raising homework completion rate and scores on GRE practice questions for students in a study strategies course. These students were chosen because they had been experiencing academic problems. Although both types of one-shot attribution training (video and live) have proven to be effective (Holschuch, Nist, \& Olejnik, 2001; Robertson, 2000; Wilson \& Linville, 1982), no known research has been conducted that involves carrying out both live and video-based attribution training for the purpose of comparing the effectiveness of each approach. This research allowed us to compare a video, live, and control group to see whether the presentation mode of attribution training made a difference on student effort as defined by homework completion rate and pre and post scores on GRE practice questions.

In Research Question One, looking at the difference between the live, video, and control groups, no significant differences were found between the pre and post scores of the GRE practice score means. However, there was a significant difference between the pre and post measures of homework completion rate for the live, video, and control groups. More specifically, a difference was observed between the pre and post percentages of homework completion rate when comparing the live and control groups. The participants who received the live presentation scored 13.2 percentage points higher than the control group on homework completion rate after receiving attribution training. Students who received the video presentation scored only 9.02 percentage points higher than the control. This data revealed that the live group scored 4.2 percentage points better 
than the video group. However, this difference in means was not statistically significant.

Research Question Two added another variable to consider when assessing the effectiveness of attribution training on GRE practice score and homework completion rate. This question evaluated the impact of time of semester on student effort (GRE practice score and homework completion rate). Research has not examined how time of semester impacts the effectiveness of attribution training. Previous attribution training research, however, conducted with undergraduate students at the end of the semester, (immediately preceding the final exam) yielded effects in the ability to make positive changes in student attributions (Holschuh, Nist, \& Olejnik, 2001). Although no known research on attribution training has been completed that takes time of semester into account, one would expect that the earlier the intervention (attribution training) occurs, the more impact the training will have on changing student behavior (effort). This research found no effects of time of semester on GRE practice score. Time of semester, however, did effect performance on homework completion rate. More specifically, students scored 18.6 percentage points higher on homework completion rate when training was carried out at beginning as compared to the end of the semester.

Students may have been less responsive to attribution training at the end of the semester (Week 12) because their behavior (effort) would have a lesser impact on grades this late in the semester. Therefore, they may have felt that making changes at 12 weeks would not be productive because a large portion of their grade had already been determined by prior performance in the class.

Research Question Three looked at the impact the gender of the script reader had on GRE practice scores and homework completion rates. There was a significant main 
effect related to gender of the reader on GRE practice scores. When the male presented the attribution training, participants performed 15 points higher on GRE practice score. However, gender of the presenter had no significant effect on homework completion rate. Although research has examined how attribution training effects gender of the participant (Beyer, 1998; Craske, 1985; Holschuh, Nist, \& Olejnik, 2001), there is no current research to suggest that gender of the script reader or gender of the individual carrying out attribution training has a differential impact on student behavior. Since no research has examined these data, we can only speculate as to why GRE scores increased more when a male carried out attribution training. In this research, it is possible that the male was more influential on GRE practice question performance because the male presenter was better at delivering the information. It is also possible that the male presenter was able to develop stronger rapport with the students as compared to the female presenter. In order to get a better idea regarding the influence of gender on student performance, multiple male and female script readers would need to be utilized. These results need to be duplicated before claims can be made stating that male presenters are superior to female presenters.

Research Question Four looked at the effect of gender of the participant on GRE practice score and homework completion rate. The purpose in posing this question was to evaluate whether or not males were more impacted by attribution training than females, as previous research obtained varying results (Wilson \& Linville, 1982; 1985). The present study supports the first study (Wilson \& Linville, 1982), which did not observe gender differences.

Research Question Five was not able to compare the high and low ACT/SAT 
scores with a statistical analysis when the middle was omitted because ninety-two percent of the sample had scores in the middle (one standard deviation above or below the mean). However, when median scores were used, and all students were placed in either the high or low category, no significant differences were observed for either homework completion rate or GRE practice score. This is contrary to findings of a meta-analysis on attribution training that suggests that students with high ability have greater increases in performance on dependent measures of academic performance following attribution training when compared to students with low ability (Robertson, 2000).

\section{Limitations}

There were some limitations encountered in this study. First, limitations related to the sample will be addressed. The sample used was one of convenience. Students who agreed to participate determined what students would be involved in the study. In

addition, all students who participated in the study were undergraduate freshman students ( $N=93$ ) enrolled in a study strategies course at a mid-sized university in the Northeastern region of the United States. Therefore, this study is only generalizable to this population of students. Nonetheless, this research is beneficial because several universities have similar study strategies sections for struggling freshman. As a result, developers and instructors of these classes would benefit from knowing whether or not attribution training has benefits in regards to student performance on academic-based tasks and student effort.

Second, although similar research has produced successful outcomes with both school-aged and undergraduate students, previous studies conducted with undergraduate students did not consist of struggling students (Wilson \& Linville, 1982; 1985; Holschuh, 
Nist, \& Olejnik, 2001). It is possible that significant results were not observed in the current study with struggling, undergraduate-level students because these students may have had years of failure during elementary and secondary school. Failure over many school years may have fostered a pattern of negative attributions. For example, although Robertson's (2000, p. 132) review of research on attribution training with school-aged children concluded that "attribution training can be applied to classroom settings to assist 'at risk' children with poor attributional styles," attributions may be harder to change with 'at risk' college students who may have utilized negative attributions for several years. Therefore, when working with struggling students, it may be more beneficial to start changing attributions in grade school before children have been exposed to several years of failure. However, researchers cannot assume that students who are struggling in college also struggled in elementary or secondary school. More research with struggling students is needed in order to learn more about the effectiveness of attribution training with this population of students.

Another limitation related to the sample has to do with the quality of students that participated and the way in which the present study accounted for student ability. Since the most recent meta-analysis on attribution studies conducted with school-aged children concluded that attribution training works best with students who have the ability to do well academically but are struggling with academics due to insufficient effort or lack of proper study strategies (Robertson, 2000), this research controlled for ability by separating students into those who received either low or high SAT/ACT scores. However, this may not be the best way to account for ability because we cannot assume low ability due to high or low SAT scores. Furthermore, many of the students in the 
study strategies class were placed in the class due to low ACT/SAT scores; therefore, this sample of students had a high rate of low ACT/SAT scores in comparison to the general population of college students. For example, the average college student has either an ACT of 20 or an SAT of 1000, however in the present sample of students, only five of the 92 students had ACT or SAT scores at or above the average.

Third, when reviewing the data, it is important to note that statistical significance may have been absent due to lack of power. Sample sizes were small for all three groups, particularly when looking at the pre and post differences in GRE practice score means. Sample sizes for the GRE practice score means were 18 participants in the live condition, 20 participants in the video condition, and 13 participants in the control condition. Similarly, when looking at homework completion rate means, there were only 31 participants in the live condition, 29 participants in the video condition, and 32 participants in the control condition. Since sample sizes were small, there is a higher chance of a Type II error (occurs when a researcher fails to reject the null hypothesis that is actually false). It is quite possible that if sample sizes were larger, significance would have been observed among the three groups.

Another limitation has to do with whether or not the live group was truly more effective. The live group may have done better because this group had a chance to ask questions following training. The class as a group was required to ask the live presenter at least one question following the presentation. Therefore, they were more involved in the training. It is possible that when participants asked questions, they felt more of a connection to the presenter and as a result, they were more influenced by this person. In addition, having the presenter respond to questions may have made the participants feel 
like the presenter was more genuine.

It is important to note that there are also several limitations in interpreting the GRE practice score measures. First, there were a lot of nonreports of GRE practice scores for the posttest, especially for the control group. Only three individuals reported pre and post scores for the control group at the end of the semester (Week 12). Therefore, comparing the control group to the video and live group at this time period was not meaningful. The sample of students who completed both pre and post scores of the GRE practice score are as follows for the beginning of semester: live ( $\mathrm{n}=9$ ); video ( $\mathrm{n}$ = 9); control $(\mathrm{n}=10)$. Similarly, the sample sizes of students who completed both pre and post scores of the GRE practice score for the end of the semester are as follows: live $(\mathrm{n}=9)$; video $(\mathrm{n}=11)$; control $(\mathrm{n}=3)$.

The other problem with GRE practice scores is although they have been utilized in previous research (Wilson \& Linville, 1982; 1985), they are a poor measure of student effort because they are not closely tied to class content. For example, in the present study, students in the study strategies course did not practice these kinds of tasks nor did they have any assignments that review such tasks. Therefore, basing student effort on this measure makes little sense. Although, in the present study, using this dependent measure was to see whether previous research would be replicated (Wilson \& Linville, 1982), basing student effort on this measure is of little benefit. The second dependent variable, homework completion rate, was a better measure of effort because it was directly tied to classroom performance. However, this measure could have been improved if all weeks had an equal number of assignments. The number of assignments for each week is as follows: Week Five (seven); Week Seven (six); Week 11 (eight); and 
Week 13 (five). Interpreting results of the homework completion rates would have been more accurate, had the number of homework assignments been equal for each week. An additional benefit of homework completion rate over GRE practice score was a larger sample size for homework completion rate. Since teaching assistants recorded the number of homework assignments completed for each student, this dependent measure did not require student participation. Alternatively, GRE questions did require student participation because students had to be present in class on the dates that GRE practice scores were collected. Furthermore, in order for researchers to look at improvement in GRE practice score, students had to be present during two sessions (pre and post). Therefore a lot of data was lost because students were absent during either the pre or post collection of data. As a result, pre and post collections of GRE practice scores were only collected for 51 students, whereas 92 students had reports of pre and post measures of homework completion rates.

Finally, there are also problems with interpreting the results related to gender of the script reader. Only one male and one female were script readers. Therefore, the impact script readers had on the dependent variables may have been due to the quality of the script reader as opposed to the gender of the script reader.

\section{Suggestions for Future Research}

As discussed in the previous section, there are several limitations that could be addressed in future research, given more time and financial resources. This section will address how future research can better control for some of the problems with the present study. Although this research found no significant differences between video and control groups, a comparison of means revealed that students in the live presentation group did 
slightly better (four percentage points) on homework completion rate than students in the video group. Further research on attribution training is needed in order to compare video and live modes of attribution training. It is quite possible that students attend more when the presenter is physically present in the room. It may be easier for students to ignore a video as opposed to a live presenter, especially when students know that they will be expected to ask the presenter questions following the presentation. Furthermore, it would be interesting to see if live presenters are more persuasive than video presenters, even when they do not have the opportunity to ask questions. Future studies could address this issue by utilizing several live groups and dividing these groups so that in some live groups students are permitted or required to ask questions and in other groups questions are not asked. This will help identify whether or not live training is still superior to video training, even when participants do not have the opportunity to ask questions of the presenter.

In the present research time of semester appeared to have a positive impact on homework completion rate, when attribution training was carried out in the beginning (Week six) of the semester. More research is needed in order to verify if this is holds true in multiple settings. Additional research is also needed because conflicting results were observed between homework completion rate and GRE practice score. While homework completion rate improved at post-training during the first six weeks, GRE practice scores went down. One may want to look at additional dependent measures of effort and student achievement in order to see if time of semester consistently produces conflicting results on different dependent variables. Nonetheless, it is better to judge student effort based on homework completion rate in the current study because sample sizes were better for this 
dependent measure.

Although homework completion rate was a good measure of effort or student performance, other dependent variables also could have been used to measure student effort and academic performance post-training. One dependent variable that future research should consider is classroom participation. The instructors of each class could rate each student on how well they attended and contributed to discussion before and after training. Furthermore, given more time and a different sample of students, future research also could look at long-term measures of student performance. For example, if second-semester freshman or sophomores served as participants, researchers could look at grade point averages before and after training. The semester grade point averages in which the students received attribution training could serve as a short-term measure of academic performance. In addition, researchers also could look at student grade point averages for the semester immediately following training in order to see if students continued to exhibit increased performance several months following attribution training. Finally, although this research was more concerned about behavioral outcomes of attribution training, it would be beneficial to see if students' perceptions of what causes success or failure changed as a result of training. Attribution theory would predict that students would attribute success or failure more to effort as opposed to ability, luck, or task difficulty following the type of attribution training that was conducted in the present study (Dweck, 1975; Fowler \& Peterson, 1981; Holschuh, Nist, \& Olejnik, 2001).

When evaluating the effect of the gender of the script reader on student effort and performance, future research should utilize more than one male or female in order to control for quality of the script reader. For example, at least three males and three 
females should serve as script readers when trying to decide if gender of the script reader impacts student effort. Another option that may control for quality would be to have the same two script readers present to several classes. Also, future research could have students rate the script readers on a scale of one to 10 in order to rule out quality as an extraneous variable.

Students with high versus low ACT/SAT information (as a measure of ability) did not perform differently on GRE practice score or homework completion rate. Nonetheless, looking at the impact of ability in relation to attribution training is important. Future attribution training may better account for ability by using a sample of students who are more representative of the general population of college students, such as students in an introductory Biology or English course that all students are required to take. In addition, when working with college students, ability may not be the only barrier that affects students' receptiveness to attribution training. A history of academic failure in elementary, middle, and high school may also cause students to be less likely to perceive effort as the primary cause of success or failure. Researchers could obtain a history of failure by having the students complete a self-report questionnaire that measures academic success or failure. Personal information to obtain from this questionnaire could be a report of grades in elementary, middle, and high school, a presence/absence of a learning disability or processing problem, history of retentions, presence/absence of behavioral problems at school, and a close-ended statement identifying whether or not each student felt successful in elementary, middle, and high school. It is quite likely that students who have repeatedly received poor grades or students who have been retained to repeat a grade feel as though their school years are 
representative of personal failure, and they perceive themselves as less able regardless of their intellectual potential. This type of academic-based information will allow future researchers to examine the impact of a history of academic failure on the effectiveness of attribution training.

In summary, although results of this study did not reveal that attribution training has a strong, positive impact on student effort, it did reveal that live attribution training has a positive impact on homework completion rate, especially when training is carried out during the beginning of the semester. As stated earlier, statistical significance may have been low due to small sample sizes, which reduces statistical power. In addition, since the live group was the only training group that revealed a trend towards significance in comparison to the control, future research may want to reconsider using video-based attribution training. Furthermore, future investigations should take time of semester into account, as participants did significantly better on homework completion rate when training was conducted at the beginning of the semester. Additional research using larger sample sizes, additional dependent variables closely tied to effort, and long-term measures of student achievement will be needed in order to determine if the mode of attribution training and the time of semester in which training is carried out truly makes a difference on student effort and student achievement. 


\section{References}

Beyer, S. (1998). Gender differences in causal attributions by college students of performance on course examinations. Current Psychology, 17(4), 346-358.

Brownlow, S., \& Reasinger, R. D. (2001). Putting off until tomorrow what is better done today: Academic procrastination as a function of motivation toward college work. Journal of Social Behavior and Personality, 16(1), 15-34.

Carr M., \& Borkowski, J. G. (1989). Attributional training and the generalization of reading strategies with underachieving children. Learning and Individual Differences, 1(3), 327-341.

Chapin, M., \& Dyck, D. G. (1976). Persistence in children’s reading behavior as a function of $\mathrm{N}$ length and attribution training. Journal of Abnormal Psychology, 85, 511-515.

Crandall, V. C., Katkovsky, W., \& Crandall, V. J. (1965). Children’s beliefs in their own control of reinforcements in intellectual-academic achievement situations. Child Development, 36, 91-109.

Craske, M. L. (1985). Improving persistence through observational learning and attribution retraining. British Journal of Educational Psychology, 55, 138-147.

Craven, R. G., Marsh, H. W., \& Debus, R. L. (1991). Effects of internally focused feedback on enhancement of self concept. Journal of Educational Psychology, 83, $17-27$.

Dweck, C. S. (1975). The role of expectations and attributions in the alleviation of learned helplessness. Journal of Personality and Social Psychology, 31, 674-685.

Findley, M. J., \& Cooper, H. M. (1983). Locus of control and academic achievement: A 
literature review. Journal of Personality and Social Psychology, 64, 419-427.

Fowler, J. W., \& Peterson, P. L. (1981). Increasing reading persistence and altering attributional style of learned helpless children. Journal of Educational Psychology, 73, 251-260.

Frieze, I. H. (1976). Causal attributions and information seeking to explain success and failure. Journal of Research in Personality, 10, 293-305.

Hjelle, L. (1970). Internal-external control as determinants of academic achievement. Psychological Reports, 26, 326.

Holschuh, J. P., Nist, S. L., \& Olejnik, S. (2001). Attributions to failure: The effects of effort, ability, and learning strategy use on perceptions of future goals and emotional responses. Reading Psychology, 22, 153-173.

Kaiser, D. L. (1975). Internal-external control and causal attributions of own and others' performance. Psychological Reports, 37, 423-426.

Little, T. D., Stetsenko, A., \& Maier, H. (1999). Action-control beliefs and school performance: A longitudinal study of Moscow children and adolescents. International Journal of Behavioral Development, 23(3), 799-823.

Martinez, R., \& Sewell, K. W. (2000). Explanatory style as a predictor of college performance in students with physical disabilities. Journal of Rehabilitation, 66(1), 30-36.

Maqsud, M. (1993). Relationships of some personality variable to academic attainment of secondary school pupils. Educational Psychology, 13(1), 11-18 [On-line]. Available: EBSCOhost.

Menec, V.H., Perry, R.P., Struthers, C.W., Schonwetter, D.J., Hechter, F.J., \& Eicholz, 
B.L. (1994). Assisting at-risk college students with attributional retraining and effective teaching. Journal of Applied Social Psychology, 24 (8), 675-701.

Messer, S. B. (1972). The relation of internal-external control to academic performance. Child Development, 43, 1456-1462.

Nicholls, J. G. (1976). Effort is virtuous, but it’s better to have ability: Evaluative responses to perceptions of effort and ability. Journal of Research in Personality, 10, 306-315.

Pearl, R. (1982). LD children's attributions for success and failure: A replication with a labeled LD sample. Learning Disability Quarterly, 5, 173-176.

Perry, R.P., \& Penner, K.S. (1990). Enhancing academic achievement in college students through attribvutional retraining and instruction. Journal of Educational Psychology, 82, 262-271.

Peterson, C., \& Barrett, L. C. (1987). Explanatory style and academic performance among university freshman. Journal of Personality and Social Psychology, 53(3) 603-607.

Robertson, J. S. (2000). Is attribution training a worthwhile classroom intervention for K12 students with learning difficulties? Educational Psychology Review, 12(1), 111-134.

Rotter, J. B. (1990). Internal versus external control of reinforcement: A case history of a variable. American Psychologist, 45(4), 489-493.

Russell, D. (1982). The Causal Dimension Scale: A measure of how individuals perceive causes. Journal of Personality and Social Psychology, 42, 1137-1145. 
Seligman, M. E. P. (1975). Helplessness: On depression, development, and death. San Franscisco: Freeman.

Weiner, B. (1972). Theories of motivation. Chicago: Rand McNally College Publishing Company.

Weiner, B. (1979). A theory of motivation for some classroom experiences. Journal of Educational Psychology, 71, 3-25.

Weiner, B. (1994a). Integrating social and personal theories of achievement striving. Review of Educational Research, 64(4), 557-573.

Weiner, B. (1994b). Ability versus effort revisited: The moral determinants of achievement evaluation and achievement as a moral system. Educational Psychologist, 29(3),163-172.

Weiner, B., Cook, R. E., Heckhausen, H., \& Meyer, W. (1971). Causal ascriptions and achievement behavior: A conceptual analysis of effort and reanalysis of locus of control. Journal of Personality and Social Psychology, 2(2), 239-248.

Weiner, B., \& Kukla, A. (1970). An attributional analysis of achievement motivation. Journal of Personality and Social Psychology, 15, 1-20.

Weiner, B., \& Peter, N. (1973). A cognitive-developmental analysis of achievement and moral judgments. Developmental Psychology, 9(3), 290-309.

Wilson, T. D., \& Linville, P. W. (1982) Improving the academic performance of college freshman: Attribution therapy revisited. Journal of Personality and Social Psychology, 42(2) 367-376.

Wilson, T. D., \& Linville, P. W. (1985). Improving the academic performance of college freshman: Attribution therapy revisited. Journal of Personality and Social 
Psychology, 49(1) 287-293.

Yasutake, D., Bryan, T., \& Dohrn, E. (1996). The effects of combining peer tutoring and attribution training on students' perceived self-competence. Remedial and Special Education 17(2), 83-91. 


\section{Appendix A}

\section{Cover Letter}

The current research study is being conducted in order to fulfill the requirements for a doctoral dissertation. The purpose of this study is to identify the effects of attribution training on academic performance in undergraduate students. Student responses provided for the basis of this study will remain anonymous. Each student will be identified by a four-digit code, which in no way identifies the individual. Student's names or other identifying information will not be present in any written or oral presentations or any documents that accompany this research. When completing this research, you are not required to answer any or all questions. Refusal to participate in the study will not effect student grades, class standing, or job status. Students can refuse to participate or withdraw their participation at any time.

If you have questions or would like to request further information about the study please contact:

Tasneem Edmonds 233 Bradley Street Morgantown, WV 26505 (304) 599-5186 tedmonds@mix.wvu.edu 


\section{Appendix B}

Script for Video and Live-Based Script Readers: Revised scenario modeled after Holschuh, J. P. (2001) et al.

Hello everyone, my name is Jen (Mike) Thomas and I am a sophomore, majoring in business. Today I would like to talk to you guys about my initial struggles in college. Like many of you, my freshman year was not a walk in the park. I had several downfalls before finding my path to college success. One of these downfalls has to do with my struggles in English 101, which as you know, all of us have to take as part of our core coursework. Going into the class, my plan was to make an "A" in the course. However, I ended up making an "F" in English 101 and had to take the course over.

I now know why I failed. I simply did not put in enough effort. Although I wanted to do well, I went out a lot and made up every excuse I could think of not to study and work on this course. But after the fact, I decided that I would try harder the next time around. In a nutshell, my failure told me that I did not put in the needed effort. I knew that I had the ability to do better in the course. I just had to suck it up and admit that I did not put forth the needed effort.

The next time around, I did what I knew I needed to do all along. The first thing that I did was talk to my professor about my prior struggles in English. He suggested that I go to the writing center on campus and get help. I was a little reluctant because with all of my other classes, I knew it would be hard to find the extra time to get tutored in Writing. After thinking about my dilemma for a couple of days, I had made my decision. I knew that I had the ability to do better in this class, so I was sure that if I put in the extra effort and went for tutoring at the writing center, my grade this time around would be 
much better.

Reluctantly, I took my first trip over to the writing center. I brought along some of my failing papers from the previous semester so they could see what my writing skills were like. Greg, a staff member at the writing center, told me that I would be able to learn the skills I needed to do better in English 101 if I came to the center every other week during the course of the semester. During the first meeting, Greg went over some of the mistakes I had made on my previous papers and he showed me how to correct these errors. I continued going back over the course of the semester, and various staff members at the writing center helped me with my English 101 assignments. To my surprise, on my first English assignment, I brought my F's from the first semester up to a $\mathrm{C}+$ on this paper. I continued going to the center and working hard in the course and I ended up with a B. I was thrilled. Now I feel like my troubles in writing are finally over. I am so glad I put in the extra effort and went to the writing center.

For any of you students that are in a class where you are struggling, I encourage you to seek help so you can get the skills you need to do better. Some people believe that certain people are doomed to failure in certain subjects, no matter how hard they try. Often times you hear people say "I am just not good in math, science, writing etc and so on, but the reality is, most people can do well in these subjects if they are willing to give them extra attention. Just because you get an F on a test or assignment, does not mean you are doomed to failure in a class. With a little time and effort, you can succeed, I am living proof. I am happy to say that as a sophomore, I am finally on the Dean's list. 